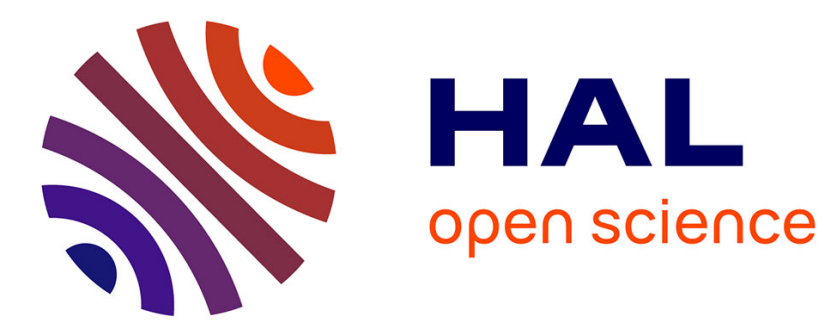

\title{
Commercial Piracy and Intellectual Property Policy
}

Ilkka Kiema

\section{To cite this version:}

Ilkka Kiema. Commercial Piracy and Intellectual Property Policy. Journal of Economic Behavior and Organization, 2008, 68 (1), pp.304. 10.1016/j.jebo.2008.03.005 . hal-00618794

\section{HAL Id: hal-00618794 https://hal.science/hal-00618794}

Submitted on 3 Sep 2011

HAL is a multi-disciplinary open access archive for the deposit and dissemination of scientific research documents, whether they are published or not. The documents may come from teaching and research institutions in France or abroad, or from public or private research centers.
L'archive ouverte pluridisciplinaire HAL, est destinée au dépôt et à la diffusion de documents scientifiques de niveau recherche, publiés ou non, émanant des établissements d'enseignement et de recherche français ou étrangers, des laboratoires publics ou privés. 


\section{Accepted Manuscript}

Title: Commercial Piracy and Intellectual Property Policy

Author: Ilkka Kiema

PII:

DOI:

S0167-2681(08)00069-3

Reference: doi:10.1016/j.jebo.2008.03.005

JEBO 2186

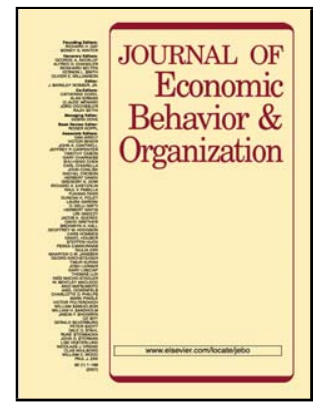

To appear in: Journal of Economic Behavior \& Organization

Received date: $\quad 15-4-2007$

Revised date: $\quad 14-3-2008$

Accepted date: $\quad$ 21-3-2008

Please cite this article as: Kiema, I., Commercial Piracy and Intellectual Property Policy, Journal of Economic Behavior and Organization (2007), doi:10.1016/j.jebo.2008.03.005

This is a PDF file of an unedited manuscript that has been accepted for publication. As a service to our customers we are providing this early version of the manuscript. The manuscript will undergo copyediting, typesetting, and review of the resulting proof before it is published in its final form. Please note that during the production process errors may be discovered which could affect the content, and all legal disclaimers that apply to the journal pertain. 


\section{Commercial Piracy and Intellectual Property Policy*}

JEL codes and keywords: O34 (Intellectual Property rights), L84 (Information and Internet Services; Computer Software), Piracy

Corresponding author:

Ilkka Kiema

Researcher

Department of Economics / RUESG

P. O. Box 17 (Arkadiankatu 7)

00014 University of Helsinki

FINLAND

Tel. (office): +358919128748

Tel. (mobile): +358445488991

Fax: +358919128742

e-mail: $\underline{\text { ilkka.kiema@helsinki.fi }}$

\footnotetext{
* I would like to express my gratitude to Rune Stenbacka, Erkki Koskela, Mikko Mustonen, and Juuso Välimäki for their helpful comments on the earlier versions of this paper.
} 


\title{
Commercial Piracy and Intellectual Property Policy
}

\begin{abstract}
I discuss the competition between a copyright owner and several commercial pirates who sell copies of the same information good to consumers. I view the increased risk of a punishment that offering a pirate copy to a consumer causes as an advertising cost whose value is chosen by the government. The structure of the market for pirate copies is affected also by fixed costs that are caused by punishments or DRM systems. I present a systematic analysis of the effects of these policy variables and the quality of pirate copies on the market for the considered information good.
\end{abstract}

\section{Introduction}

The distribution of illegal pirate copies of information goods might have a variety of motives. Such copies are distributed on the one hand by the members of peer-to-peer networks, who deliver digital goods on the Internet without monetary compensation and who are motivated by, for example, a feeling of identification with the other network members, and on the other hand by commercial pirates who are, more conventionally from the perspective of the economist, motivated by the revenue that results from their activities. Somewhat less obviously, the consumers of an 
information good might also form a club, which buys a single copy of an information good, produces copies of it, and distributes one of them to each club member. ${ }^{1}$

Given that both commercial and non-commercial forms of piracy are illegal, there is no obvious way of estimating the extent to which pirate copies of information goods are sold rather than distributed for free or the effects of commercial piracy on the profits of copyright owners. Nevertheless, the International Federation of the Phonographic Industry (IFPI) has estimated that approximately $37 \%$ of all the [music] CDs that were purchased in 2005 globally were pirate copies. ${ }^{2}$ However, in the case of the software industry, it is more difficult to find estimates of the prevalence of commercial piracy.

The Business Software Alliance (BSA) publishes yearly a piracy study that contains estimates for the piracy rate (i.e. the ratio of the number of pirated software units to the total number of installed software units) for different countries of the world, as well as for different regions of the world. For example, according to the BSA the worldwide piracy rate was $35 \%$ in $2005 .{ }^{3}$ However, such estimates do not make a

1 For the producer of the first copy of the information good, this practice resembles a situation in which the club members buy a single copy of an information good and use it successively. The latter practice is legal when the considered product is, for example, a book, a journal, or a video tape, and in both cases, the producer of the first copy might be able to appropriate indirectly a part of the value that the good has for its consumers. See Varian (2000).

2 International Federation of the Phonographic Industry (IFPI), The Recording Industry 2006 Piracy report, p. 4. Available at http://www.ifpi.org/sitecontent/library/piracy-report2006.pdf, accessed on October 29, 2006.

3 Third Annual BSA and IDC Global Software Piracy Study, p. 13. Available at 
distinction between commercial and non-commercial forms of piracy. ${ }^{4}$ Nevertheless, the other surveys of the BSA suggest that both the commercial and non-commercial forms of software piracy are of considerable economic significance. ${ }^{5}$

http://www.bsa.org/globalstudy/upload/2005\%20Piracy\%20Study\%20-

\%20Official\%20Version.pdf, accessed on April 13, 2007.

${ }^{4}$ This is because the estimates of the BSA have been calculated from an estimate of the total number of installed software units, which is based on the number of the sold hardware units and surveys concerning their average software load, and an estimate of the number of the sold software units, which is based on information concerning the market revenues of software vendors and software pricing. See Third Annual BSA and IDC Global Software Piracy Study, p. 14.

5 In one of such surveys, the BSA has investigated the attitudes of the online consumers from six different countries towards spam, commercial emails that they have received without requesting or signing up for them (BSA, Consumer Attitudes Toward Spam in Six Countries, 2004, available at http://www.bsa.org/usa/events/loader.cfm?url=/commonspot/security/getfile.cfm\&pag $\underline{\text { eid }=20654}$, accessed on April 13, 2007). In each country, more than $80 \%$ of the respondents stated that they had received spam that was concerned with computer software (ibid., p. 6), and $27 \%$ reported that, in the product category "computer software", they had "purchased an item or taken advantage of an offer" that was suggested to them in spam (ibid., p. 12). Only $31 \%$ of the respondents stated that they agreed with the statement that they would "never buy commercial software using this method because it is most likely unlicensed and illegal" (ibid., p. 16). 
There is a relatively large economic literature on end-user copying. ${ }^{6}$ Dyuti S.

Banerjee has recently put forward several closely related models of the competition between a monopolist (i.e., the copyright owner) and a single commercial pirate (2003, 2006a, 2006b), but it nevertheless seems that until now economists have given much less attention to commercial piracy than to end-user copying. ${ }^{7}$ Below I shall put forward a model of the competition between the copyright owner and several commercial pirates, to whom I shall refer as bootleggers.

The production costs of pirate copies are low, and in the case of the pirate copies that are distributed in an electric form via the Internet they are almost zero. Accordingly, if intellectual property rights are not enforced, the prices of pirate copies can be expected to fall to zero via Bertrand competition. However, when bootleggers are in danger of being punished for their activities, it may be costly for them to inform potential consumers of their products, since this may increase the risk of being caught and receiving a punishment. For example, if an illegally operating Internet site that offers pirate copies of software products for sale informs its potential customers by sending e-mail messages to randomly chosen addresses, the risk of a punishment is increased by each message. In this case the expected cost from a punishment is analogous to an advertising cost, which explains the positive price of pirated information goods.

Information goods can be protected not only by copyright and other intellectual property rights but also by digital rights management (DRM) systems. Digital rights management tools can, broadly speaking, be divided into cryptography (i.e. the

\footnotetext{
6 For a survey, see Peitz and Waelbroeck (2006a).

7 See, however, Yao (2005), which discusses counterfeiting on a more general level, without restricting attention to counterfeited information goods.
} 
distribution of information goods in an enciphered format) and watermarking (i.e. embedding information into a digital product in such a way that each copy of the good becomes different). ${ }^{8}$ Watermarks can be used to track down the person who has originally bought the legitimate copy of an information good from which the pirate copies on the market have been produced, which makes it easier penalize commercial pirates. ${ }^{9}$ Clearly, a cryptographic device causes a fixed cost for a commercial pirate, but the costs of watermarking can be either fixed or variable: if a bootlegger removes the watermark, its removal causes a fixed cost, but if she sells watermarked information goods, the risk caused by the watermark increases with the number of the copies that she sells.

Below I shall analyze the effects of DRM systems and the policy instruments of the government on the profits of the bootleggers and the copyright owner. In the model the "advertising costs" that are caused by an increased risk of legal sanctions also keep the price of pirate copies positive when there are several bootleggers on the market. Accordingly, the model differs from previous work in the same field in so far

${ }^{8}$ For a survey, see Eskicioglu and Delp (2001).

${ }^{9}$ Since a large-scale commercial pirate can be expected to be able to break down a cryptographic system, watermarking seems to be the more relevant DRM tool in the context of large-scale commercial piracy (cf. Eskicioglu and Delp (2001), pp. 683684). See also Park and Scotchmer (2005), which contains an analysis of DRM and of the different effects of the use of shared and independent DRM systems on end-user piracy. 
that it provides tools for analyzing also the market structure of the market for pirate copies as well as its effects on the market for legitimate copies. ${ }^{10}$

\section{The Main Features of the Model}

The agents of the model that is considered below are 1) a copyright owner who sells copies of an information product legally, 2) K potential bootleggers who wish to sell illegitimate pirate copies of the same good, and 3) a unit mass of consumers, which is indexed by $\theta \in[0,1]$. The bootleggers can inform the consumers of the availability of their products by sending them advertisements at random. As a paradigmatic example of a situation of this type, one might think of an illegally operating Internet site that sends advertisements of pirated software products to randomly chosen e-mail addresses. The sending of an advertisement is associated with a cost $b$, which should be interpreted as the increase in expected cost of punishment that sending a single advertisement causes.

10 See Banerjee (2003, 2006a, 2006b), who discusses several closely related models of the competition between the copyright owner and a single pirate. In these models the pirate copies are of a lower quality than legitimately bought copies, and this stops the price of the good from sinking to zero through Bertrand competition. However, in these models the number of the pirates is by assumption 1, and they do not address the question why the price of the pirate copies does not sink to zero through a Bertrand competition between the pirates (rather than between them and the copyright owner). 
More precisely, I shall assume that sending an advertisement causes an increase $\alpha$ in the risk of being caught, that the bootlegger receives a punishment $G$ if she is caught, and that the bootleggers are risk neutral. In this case the "advertising cost" $b$ is given by ${ }^{11}$

(1) $b=\alpha G$.

Any combination of $\alpha$ and $G$ that corresponds to the same value of $b$ has the same effects on the markets for both legitimate and pirate copies, and accordingly I shall analyze below the effects of the choice of $b$ (rather than of $\alpha$ and $G$ ) for these markets. $^{12}$

I shall assume that the bootleggers cannot keep track of the consumers to whom they have already sent an advertisement. Rather, each of the bootleggers sends each of the advertisements with the same probability to each consumer. ${ }^{13}$ This implies that a

${ }^{11}$ For a discussion of the econometric problem of actually constructing an index that measures the strength of legal software protection in a given country, see Andrés (2006, pp. 34-37).

12 It is easy to see that the problem of choosing $\alpha$ and $G$ so that the monitoring costs of the government are minimized, given the constraint (1), does not have a welldefined solution: if an increase in monitoring causes costs for the monitoring authorities, but an increase in punishments (such as fines) does not, any increase of $G$ and decrease in $\alpha$ that keeps (1) valid seems always beneficial from the perspective of the government. Hence, it seems that a meaningful discussion of the optimal choice of $\alpha$ and $G$ would require a more general model.

13 In a more general model it could be assumed that the bootleggers would be able to target their advertisements at the consumers who are likely to buy a pirate copy. This would change the demand function (8), but it is easy to see that the analysis of the 
bootlegger might send to the same consumer several advertisements in which the product is offered for sale at different prices. This assumption is particularly plausible in the context of trade on the Internet since the potential customers of bootleggers might have several e-mail addresses. In addition, if the consumers are divided into groups whose members inform each other of the advertisements that they have received, a single advertisement might reach individuals with different e-mail addresses, and in this case a bootlegger cannot eliminate the possibility that the same group of consumers receives many advertisements from her. In this case one should interpret $b$ as the average cost of reaching a single consumer with a single advertisement.

This implies that the description of the competition between the bootleggers resembles the classical model of advertising by Gerard R. Butters (1977). ${ }^{14}$ Accordingly, in the current model there will be price dispersion in the market for the

market for pirate copies for a fixed value of $p_{M}$ (i.e. the results which are summarized in Proposition 1 below) would still remain valid. However, the analysis of the optimization problem of the copyright owner would become essentially more complicated.

14 See also Tirole (1989, pp. 290-294). The current model and Butters's model of advertising can both be contrasted with Varian's model of sales (Varian 1980), in which the potential customers are divided into informed and uninformed consumers, and the informed consumers know the prices chosen by all the sellers, whereas the uninformed consumers know only the price set by the seller from whom they make their purchase. 
advertised product. ${ }^{15}$ Clearly, this result is quite plausible in the context of the illegal business model of the bootlegger: since the bootleggers do not necessarily know the prices set by their competitors or the demand that they face, they have an incentive to find the optimal price level experimentally by specifying different prices in different advertisements. Further, when peer-to-peer networks are viewed as a limiting case of commercial piracy, also the fact that identical information goods are sold by pirates and distributed for free on peer-to-peer networks is seen to exemplify price dispersion in the market for pirate copies.

However, the current model differs from Butters's model in several essential respects. In the currently considered model there is an oligopoly in the market for pirate copies, ${ }^{16}$ and since the "advertising costs" have been meant to represent the expected costs from a punishment for copyright violation, it will be for simplicity assumed that the copyright owner may advertise for free and that all consumers have the option of buying the product from her. In addition, since I wish to model a situation in which only a part of the consumer pool prefers buying a pirate copy to buying a legitimate copy, unlike Butters I shall assume that the reservation prices of the consumers differ.

I shall assume that the reservation price of the consumer $\theta$ (where $0 \leq \theta \leq 1$ ) for a legitimate copy of the good is $\theta$ and that for a pirate copy her reservation price is $q \theta$,

15 More precisely, there is price dispersion whenever there are more than one active bootleggers on the market. See Proposition 1 below.

${ }^{16}$ Butters is for the most part concerned with a model with a large number of sellers with no market power. See, however, Appendix A (ibid., pp. 483-488) for a short discussion of an oligopoly of $N$ sellers. 
where $q \in(0,1)$ is a constant. ${ }^{17}$ In Banerjee (2003, p. 100), from which I have borrowed this notation, it was assumed that $q$ corresponds to the probability with which a pirate copy is operational. However, here the parameter $q$ represents not only the fact that a pirated product might be technically of a worse quality than a legal one or not operational at all, but also a consumer preference for legally bought copies for ethical reasons because there might be legal sanctions against using (and not just against selling) pirate copies or because buying a pirate copy requires giving credit card information to criminals.

Different values of $q$ seem plausible in the different applications of the model. One might expect that, for example, music files downloaded from a peer-to-peer network are experienced by their users to be of an almost identical quality with legally bought ones, and in this case it seems plausible to assume that $q \approx 1$. However, considerations other than technical quality seem more relevant in the case of illegally bought software products, and this motivates the assumption that such software products correspond to essentially lower values of $q$. Finally, if one applied the current model to pirate copies of other branded articles rather than information goods, they could be associated with even lower values of $q$.

${ }^{17}$ Clearly, one could also assume that consumers differ also with respect to $q$ and not just with respect to $\theta$. For example, one could follow Chen and Png (2003, p. 110) by assuming that some consumers reject pirate copies on ethical grounds while others do not. The remarks made in footnote 13 above apply also to models of this type; our discussion of the market for pirate copies for each fixed value of $p_{M}$ can be generalized in an obvious way to such models, but choosing the optimal $p_{M}$ would be essentially more complicated in their context. 
In the model a copyright owner and $K$ potential bootleggers play the following fourstage leader-follower game. ${ }^{18}$

1) The copyright owner sets the price $p_{M}$ of legitimate copies.

2) Each potential bootlegger decides whether to enter the market and to pay a fixed cost $F$.

3) The bootleggers (if any) who have entered decide to send a certain number of the advertisements to randomly chosen consumers. The bootleggers are not constrained to offer the product at the same price in different advertisements.

4) The consumers choose whether to buy the product. If a consumer $\theta$ has not received any advertisements, she will buy the product from the copyright owner if $\theta-p_{M} \geq 0$, and she will buy nothing otherwise. If a consumer $\theta$ has received at least one advertisement, and if the lowest price suggested in the advertisements that she has received is $p$, she will buy the product from the copyright owner if $\theta-p_{M} \geq \max \{0, q \theta-p\}$. If this is not the case, she will buy the product from a bootlegger at price $p$ if $q \theta-p \geq 0$. If neither of these conditions is valid, she will not buy anything. If the consumer buys the product from a bootlegger at price $p$ and if there are several bootleggers who have offered the product at price $p$ to her, she will choose one of them at random.

${ }^{18}$ See Banerjee (2003), which contains a discussion of both a leader-follower game and a Bertrand game in the context of a model with a single pirate. 
In this game the aim of the copyright owner is to maximize her profit, which is simply equal to her revenue

$$
R_{M}\left(p_{M}\right)=p_{M} D_{M}\left(p_{M}\right)
$$

where $D_{M}\left(p_{M}\right)$ is the demand function of the copyright owner, and each bootlegger $i \in\{1,2, \ldots, k\}$ aims at maximizing the profit $P_{i}=R_{i}-b A_{i}$, where $R_{i}$ is the revenue of the $i$ th bootlegger and $A_{i}$ is the number of the advertisements that she sends.

Obviously, in equilibrium the number of the bootleggers who actually enter the market will be

$$
k\left(p_{M}\right)=\max \left\{k^{\prime} \mid R_{i}-b A_{i} \geq F \text { when the number of the bootleggers is } k^{\prime}\right\}
$$

Part 4) of the definition of the considered game implies that if the cheapest price at which a consumer $\theta$ can buy the considered good from a bootlegger is $p$, she will buy it from the copyright owner if and only if

$$
\theta \geq \frac{p_{M}-p}{1-q} \text { and } \theta \geq p_{M}
$$

and from the bootlegger if and only if

$$
\theta<\frac{p_{M}-p}{1-q} \text { and } q \theta \geq p
$$

Clearly, (4) implies that there are consumers who are willing to buy the product from a bootlegger for the price $p$ only if $\left(p_{M}-p\right) /(1-q)>p / q$. This condition, which must be valid for all advertisements in equilibrium, is equivalent to

$$
q p_{M}>p
$$

If the condition (6) is valid for the cheapest price $p$ that is suggested in the advertisements that the consumer $\theta$ has received, then it will be the case that 
if $\theta<p / q$, the consumer does not buy anything,

if $p / q \leq \theta<\left(p_{M}-p\right) /(1-q)$, the consumer buys a pirate copy for price $p$,

if $\theta \geq\left(p_{M}-p\right) /(1-q)$, the consumer buys a legitimate copy.

I shall denote the demand function of the pirate copies by $x(p)$. More precisely, I shall let $x(p)$ denote the proportion of the consumers who would buy a pirate copy at the price $p$ if $p$ is the cheapest price suggested to them in the advertisements that they have received. Clearly, (7) implies that

$$
x(p)=\left\{\begin{array}{ll}
x_{A}(p), & p<q+p_{M}-1 \\
x_{B}(p), & p \geq q+p_{M}-1
\end{array}= \begin{cases}(q-p) / q, & p<q+p_{M}-1 \\
\left(q p_{M}-p\right) /[q(1-q)], & p \geq q+p_{M}-1\end{cases}\right.
$$

Here the case in which $x(p)=x_{A}(p)$ corresponds to the situation in which there are no consumers who would buy a legitimate copy if they are offered a pirate copy at price $p$. In Section 4 below it will be seen that in equilibrium the choice of $p_{M}$ by the copyright owner and the choices of the values of $p$ by the bootleggers will be such that $x(p)=x_{B}(p)$ for all the advertisements that the bootleggers send.

In the next section I deduce the equilibrium distribution of the prices of pirate copies for a given value of $p_{M}$ and a corresponding number of bootleggers $k=k\left(p_{M}\right)$. This will be utilized in the subsequent discussion of the optimization problem of the copyright owner who chooses $p_{M}$. However, as was explained in the introduction, reliable estimates of the size of the market for pirate copies and of the risk that bootleggers face of being caught are not available, and accordingly it is also interesting to study the situation in which $p_{M}$ is exogenously given. This situation can be thought of as a model of a case in which the copyright owner has no information 
concerning the bootleggers or bases her decisions on incorrect estimates of the parameters that characterize the market for pirate copies.

\section{The Market for Pirate Copies}

Below I shall assume that there are $k$ bootleggers, labeled $1, \ldots, k$, who have entered the market. Analogous to the notation used in Butters (p. 469), I define $A_{i}(p)$ to be the measure of the advertisements sent by bootlegger $i$ at a price smaller than or equal to $p, a_{i}(p)$ to be the derivative of $A_{i}(p)$ whenever it exists, and $A$ to be the total number of the advertisements.

As it was explained in Section 2 above, I assume that the bootleggers cannot keep track of the consumers to whom they have already sent an advertisement and that a bootlegger might send several advertisements to the same consumer. If there are $N$ consumers to whom the bootleggers send altogether $M$ advertisements at random, the probability with which a consumer does not receive any advertisements is

$$
\left(1-\frac{1}{N}\right)^{M}=\left(\left(1-\frac{1}{N}\right)^{N}\right)^{\eta}
$$

where $\eta=M / N$ is the number of the advertisements per consumer. Clearly, in the limit in which the number of the consumers approaches infinity, this becomes

$$
\lim _{N \rightarrow \infty}\left(\left(1-\frac{1}{N}\right)^{N}\right)^{\eta}=e^{-\eta}
$$

In the currently considered case, the mass of the consumers has been normalized to one, and the number of the advertisements that contain a price not larger than $p$ is 
denoted by $\sum_{i=1}^{k} A_{i}(p)$. Hence, the probability with which a consumer receives at least one of these advertisements is

$$
1-\exp \left(-\sum_{i=1}^{k} A_{i}(p)\right)
$$

It is easy to see that if $k=1$ (i.e. if there is just one active bootlegger on the market), she cannot have an incentive to specify different prices in different advertisements. If the single bootlegger sends $A$ advertisements that all contain the price $p$, her profit will be

$$
P_{(k=1)}=p x(p)\left(1-e^{-A}\right)-b A .
$$

Hence, in this case it is optimal for the bootlegger to advertise at the price $p$, which maximizes $p x(p)$. For reasons which will become soon obvious, I shall denote this price by $p_{\max }$, and I shall put

$$
r_{\max }=p_{\max } x\left(p_{\max }\right)
$$

Further, one can also conclude from (9) that when $k=1$, the optimal number of the advertisements is

$$
A=\ln \left(p_{\max } x\left(p_{\max }\right) / b\right)=\ln \left(r_{\max } / b\right)
$$

However, it is clear that when there are more than one active bootleggers on the market, there must be price dispersion in the market for pirate copies: if two bootleggers specified the same price in all their advertisements, each of them could increase her profits by making a sufficiently small reduction in the price. ${ }^{19}$ By the

19 As was explained in Section 2, the conclusion that the prices of pirate copies vary is quite plausible. Since the bootleggers operate on an illegal market concerning 
same argument, it can be seen that there cannot be any set of advertisements with a positive measure that would all contain the same price when there are at least two bootleggers. It is also clear that it can never be optimal for a bootlegger to specify a price that is larger than $p_{\max }$ (i.e. the price which is optimal in the absence of competition). Hence, when $k \geq 2$, the prices specified by the bootleggers correspond to a continuous distribution function $A_{i}(p)$, so that the revenue of each bootlegger is

$$
R_{i}=\int_{p_{\min }}^{p_{\max }} p x(p) \exp \left(-\sum_{i=1}^{k} A_{j}(p)\right) a_{i}(p) d p
$$

for some $p_{\min }$. The problem of maximizing this quantity can be solved by the standard tools of the analysis of variations, and its solution is given by the following proposition.

PROPOSITION 1. Suppose that the price of legitimate copies is $p_{M}$, that there are $k$ active bootleggers on the market, and that their strategies yield a symmetric Nash equilibrium relative to $p_{M}$. The largest price suggested in the advertisements has the value $p=p_{\max }$ for which $p x(p)$ is maximal, and the smallest price $p_{\min }$ suggested is then determined by the condition

$$
r_{\min }=b^{1-1 / k} r_{\max }^{1 / k}
$$

where $r_{\min }=p_{\min } x\left(p_{\min }\right)$ and $r_{\max }=p_{\max } x\left(p_{\max }\right)$. When $k \geq 2$, the number of the advertisements with a price not larger than $p \in\left[p_{\min }, p_{\max }\right]$ sent by a bootlegger $i$ is given by

which it is difficult to find detailed information, they can be expected to try to receive such information by specifying different prices in different advertisements. 


$$
A_{i}(p)=\frac{1}{k-1} \ln \frac{p x(p)}{p_{\min } x\left(p_{\min }\right)}=\frac{1}{k-1} \ln \frac{p x(p)}{r_{\min }} .
$$

Proposition 1 implies that when $k \geq 2$ the total number of advertisements sent by each bootlegger is given by

$$
A_{i}=\frac{1}{k-1} \ln \left(\frac{r_{\max }}{r_{\min }}\right)=\frac{1}{k-1} \ln \left(\left(\frac{r_{\max }}{b}\right)^{(k-1) / k}\right)=\frac{1}{k} \ln \left(r_{\max } / b\right) .
$$

A comparison of this result with (11) shows that the total number of the advertisements that the bootleggers send is independent of their number $k$. However, according to Proposition 1 an increase in $k$ shifts their price distribution downwards. The condition (13) that determines the value of smallest price $p_{\min }$ that occurs in the advertisements can be made more intuitive by observing that (12) and (14) together imply that the revenue of each bootlegger is

$$
\begin{aligned}
& R_{i}=\int_{p_{\min }}^{p_{\max }} p x(p) \exp \left(-\sum_{i=1}^{k} A_{j}(p)\right) a_{i}(p) d p \\
& =\int_{p_{\min }}^{p_{\max }} r_{\min }\left(\frac{r_{\min }}{p x(p)}\right)^{1 /(k-1)} \frac{d A_{i}(p)}{d p} d p=\int_{p_{\min }}^{p_{\max }} r_{\min } e^{-A_{i}(p)} \frac{d A_{i}(p)}{d p} d p=r_{\min }\left(1-e^{-A_{i}}\right)
\end{aligned}
$$

This result states that the revenue of each bootlegger is identical to the revenue that she would receive if she were the only bootlegger in the market and she specified the price $p_{\min }$ in all her advertisements. As $k$ increases, the increased competition in the market for pirate copies is shown by the fact that, in accordance with (13), this price sinks from the price that would be optimal in the absence of the other bootleggers, $p_{\max }$, towards the cost of sending a single advertisement, $b$.

Combining (13), (15), and (16), the revenue of the bootlegger can be also written

$$
R_{i}=r_{\min }\left(1-e^{-A_{i}}\right)=r_{\min }-r_{\min }\left(\frac{b}{r_{\max }}\right)^{1 / k}=r_{\min }-b,
$$


so the profit of each bootlegger is given by

$$
P_{i}=R_{i}-b A_{i}=r_{\min }-b-b \ln \frac{r_{\min }}{b}
$$

These results have been proved without assuming that the "demand function" $x(p)$ for pirate copies (i.e., the probability that a consumer buys a pirate copy if the lowest price suggested to her is $p$ ) is of the particular form (8). However, a more detailed analysis of the comparative statics of the market for pirate copies will depend on the form of $x(p)$.

The optimal price of a pirate copy in the absence of other bootleggers, $p_{\max }$, can be deduced from (8) by elementary means. Clearly, some of the consumers who receive an advertisement with price $p$ will prefer a legitimate copy to a pirate copy if $p>q+p_{M}-1$ and $x(p)=x_{B}(p)$, but there will no such consumers when $p<q+p_{M}-1$ and $x(p)=x_{A}(p)$. It is also clear that $p x_{A}(p)$ obtains its largest value when $p=p_{A}=q / 2$, and that $p x_{B}(p)$ obtain its largest value when $p=p_{B}=q p_{M} / 2$. Since $p_{A}>p_{B}$, it is possible to distinguish between three cases: if $p_{A}>p_{B} \geq p_{M}+q-1$, the optimal price is $p_{B}$; if $p_{M}+q-1 \geq p_{A}>p_{B}$, the optimal price is $p_{A}$; and if $p_{A}>p_{M}+q-1>p_{B}$, the optimal price must be the corner solution $p=p_{M}+q-1$. Solving for $p_{M}$, these results receive the form

$$
p_{\max }= \begin{cases}\left(q p_{M}\right) / 2, & p_{M} \leq 2((1-q) /(2-q)), \\ p_{M}+q-1, & 2((1-q) /(2-q))<p_{M}<1-q / 2, \\ q / 2, & p_{M} \geq 1-q / 2 .\end{cases}
$$

Hence, 
(20) $x\left(p_{\max }\right)= \begin{cases}p_{M} /(2(1-q)), & p_{M} \leq 2((1-q) /(2-q)), \\ \left(1-p_{M}\right) / q, & 2((1-q) /(2-q))<p_{M}<1-q / 2, \\ 1 / 2, & p_{M} \geq 1-q / 2 .\end{cases}$

Now it can be concluded from (15) that the total number of the advertisements is

$$
A= \begin{cases}\ln \left[q p_{M}^{2} /(4 b(1-q))\right], & p_{M} \leq 2((1-q) /(2-q)) \\ \ln \left[\left(\left(p_{M}+q-1\right)\left(1-p_{M}\right)\right) /(q b)\right], & 2((1-q) /(2-q))<p_{M}<1-q / 2 \\ \ln (q /(4 b)), & p_{M} \geq 1-q / 2\end{cases}
$$

The following proposition, which follows easily from these results together with Proposition 1, summarizes the comparative statics of the market for pirate copies for a fixed value of $p_{M}$ and a fixed number of active bootleggers $k$. The additional assumption $p_{M}<1-q+p_{\min }$ that is made in this proposition means that some consumers prefer buying a legitimate copy to buying a pirate copy at $p_{\min }$ (i.e. the cheapest price that pirate copies have on the market). In the next section it will be seen that this additional assumption is always valid when $p_{M}$ is chosen optimally.

PROPOSITION 2. Suppose that there are $k$ active bootleggers, that their strategies form a Nash equilibrium relative to the price of legitimate copies $p_{M}$, and that $p_{M}<1-q+p_{\min }$

(a) An increase in the price $p_{M}$ of legitimate copies increases the revenue of each bootlegger, the number of the advertisements, and the largest price $p_{\max }$ that pirate copies have on the market. If $k \geq 2$, an increase in $p_{M}$ decreases the smallest price $p_{\text {min }}$ of pirate copies on the market. 
(b) An increase in the number of the bootleggers $k$ does not affect the total number of the advertisements or the largest price of pirate copies $p_{\max }$, but it decreases $p_{\min }$, the revenue of each single bootlegger and her total revenue.

(c) An increase of the advertising cost $b$ does not affect $p_{\max }$, but it decreases the number of the advertisements, and when $k \geq 2$, it shifts $p_{\text {min }}$ upwards. In this case the profit $P_{i}$ of each bootlegger receives its maximum value for a single value $b_{E}$ of $b$ within the interval $b \in\left(0, r_{\max }\right)$. The profit $P_{i}$ is an increasing function of $b$ when $b<b_{E}$, a decreasing function of $b$ when $b>b_{E}$, and $\lim _{b \rightarrow 0} P_{i}=\lim _{b \rightarrow r_{\max }} P_{i}=0$.

(d) An increase in the quality parameter $q$ increases the maximum price $p_{\max }$ of pirate copies, the number of the advertisements, and the profits of the bootleggers. The effect of an increase of $q$ on $p_{\text {min }}$ can be either positive or negative, but it is always the case that $\partial p_{\min } / \partial q<1 / 2$.

The intuitive explanation of the last of these results is that an improvement in the quality of pirate copies on the one hand allows the bootleggers to charge higher prices, but on the other hand it also intensifies competition by increasing the number of advertisements and tending to lower the prices of pirate copies. This leads to the prediction that when the pirates have a considerable risk of receiving a punishment, an improvement in the quality of pirate copies can be expected to increase their price dispersion. The fact that $\partial p_{\min } / \partial p_{M}<0$ when $k \geq 2$ has a similar intuitive interpretation.

Part (c) of this result, which is illustrated by Figure 1 below, is concerned with the question how the profits of each bootlegger depend on the parameter $b$. This question 
is important for obvious reasons: when the number of the bootleggers on the market depends on their profits in accordance with (3), it is in the interest of the copyright owner that their profits are low. Part (c) of this result implies that when $k \geq 2$, the profits earned by the bootleggers are, for sufficiently low values of $b$, increased by an increase of $b$, which might increase the incentives to enter the market for pirate copies. I formulate this observation as a separate corollary.

[Place Figure 1 approximately here]

\section{COROLlary 1.}

(a) For each fixed value of $p_{M}$ an increase in $F$ always has a non-positive effect on the number of the bootleggers.

(b) For each fixed value of $p_{M}$ an increase in $b$ sometimes has a positive and sometimes a negative effect on the number of the bootleggers.

\section{The market for legitimate copies}

In the current model the profit of the copyright owner is equal with her revenue $R_{M}\left(p_{M}\right)=p_{M} D_{M}\left(p_{M}\right)$. The characterization of the demand $D_{M}\left(p_{M}\right)$ of the copyright owner is easy when $p_{M}>2((1-q) /(2-q))$. In this case $p_{\max }$ is according to (19) such that none of the consumers who have the option to buy a pirate copy will choose a legitimate copy, and the demand of the copyright owner is simply

$$
D_{M}\left(p_{M}\right)=e^{-A}\left(1-p_{M}\right) \text {. }
$$

Here the total number of the advertisements $A$ is given by (21), so that

$$
R_{M}\left(p_{M}\right)= \begin{cases}\left(q b p_{M}\right) /\left(p_{M}+q-1\right), & 2((1-q) /(2-q))<p_{M}<1-q / 2 \\ \left(4 b p_{M}\left(1-p_{M}\right)\right) / q, & p_{M} \geq 1-q / 2\end{cases}
$$


It is now immediately observed that when $R_{M}\left(p_{M}\right)$ is given by either of these formulas, the copyright owner can increase her profits by lowering $p_{M}$ so that these choices of $p_{M}$ cannot be optimal for her.

It is essentially more complicated to calculate $D_{M}\left(p_{M}\right)$ in the more interesting case in which $p_{M} \leq 2((1-q) /(2-q))$. Clearly, in this case the consumers $\theta$ for whom $p_{M} \leq \theta<\left(p_{M}-p_{\max }\right) /(1-q)$ will buy a legitimate copy if and only if they do not receive any advertisements. The demand from such consumers is

$$
D_{L}\left(p_{M}\right)=\left(\frac{p_{M}-p_{\max }}{1-q}-p_{M}\right) e^{-k A_{1}}=\frac{2 b}{p_{M}} .
$$

On the other hand, a consumer would buy a legitimate copy even if she could buy a pirate copy for $p_{\min }$ if $\theta \geq\left(p_{M}-p_{\min }\right) /(1-q)$. Putting

$$
p_{\min }^{\prime}=\max \left\{p_{\min }, p_{M}+q-1\right\}
$$

the demand from such consumers (if any) is seen to be

$$
D_{H}\left(p_{M}\right)=\max \left\{0,1-\left(p_{M}-p_{\min }\right) /(1-q)\right\}=1-\left(p_{M}-p_{\min }^{\prime}\right) /(1-q) .
$$

Finally, the consumers $\theta$ for whom $\left(p_{M}-p_{\max }\right) /(1-q) \leq \theta<\left(p_{M}-p_{\min }\right) /(1-q)$ will buy a legitimate copy if they do not receive an advertisement that contains a price lower than $p=p_{M}-(1-q) \theta$. The demand from such consumers is

$$
D_{\text {Med }}\left(p_{M}\right)=\int_{\left(p_{M}-p_{\max }\right) /(1-q)}^{\left(p_{M}-p_{\min }^{\prime}\right) /(1-q)} e^{-k A_{1}\left(p_{M}-(1-q) \theta\right)} d \theta
$$

Here the indexes 'L', 'Med', and ' $H$ ' refer to low, medium, and high valuation, respectively. The total demand of the copyright owner is the sum of the three demand components:

$$
D_{M}\left(p_{M}\right)=D_{H}\left(p_{M}\right)+D_{\text {Med }}\left(p_{M}\right)+D_{L}\left(p_{M}\right)
$$


Unfortunately, it seems that one cannot express the value of the integral that occurs in (27) in terms of elementary functions. The results in the rest of this section are based on a change of variables in this integral. If one puts

$$
z=\left(p_{M}-(1-q) \theta\right) /\left(q p_{M}\right),
$$

the demand component $D_{\text {Med }}\left(p_{M}\right)$ is seen to equal

$$
D_{\text {Med }}\left(p_{M}\right)=\frac{q p_{M}}{1-q} \int_{p_{\min }^{\prime} /\left(q p_{M}\right)}^{1 / 2} e^{-k A_{1}\left(q p_{M} z\right)} d z
$$

Using (8), (13), and (14), the integrated function can be expressed in the form

$$
\begin{aligned}
& e^{-k A_{1}\left(q p_{M} z\right)}=\left(\frac{p_{\min } x\left(p_{\min }\right)}{\left(q p_{M}\right) z x\left(\left(q p_{M}\right) z\right)}\right)^{k /(k-1)} \\
& =\frac{b(1-q)}{4^{1 /(k-1)} q p_{M}^{2}} \frac{1}{(z(1-z))^{k /(k-1)}}=\frac{1-q}{q p_{M}^{2}} f(z)
\end{aligned}
$$

where

$$
f(z)=\frac{b}{4^{1 /(k-1)}(z(1-z))^{k /(k-1)}} .
$$

Putting these results together, the demand of the copyright owner can now be expressed in the form

$$
D_{M}\left(p_{M}\right)=\frac{2 b}{p_{M}}+\frac{1}{p_{M}} \int_{p_{\min }^{\prime} / q p_{M}}^{1 / 2} f(z) d z+\left(1-\frac{p_{M}-p_{\min }^{\prime}}{1-q}\right) .
$$

These results make it easy to analyze the comparative statics of the profit of the copyright owner relative to the variables $b, q$, and $k$ when the price set by the copyright owner is fixed.

PROPOSITION 3. Assume that the price $p_{M}$ of legitimate copies is fixed, that there are $k$ active bootleggers, and that their strategies form a symmetric Nash equilibrium relative to $p_{M}$. 
(a) The demand $D_{M}\left(p_{M}\right)$ of the copyright owner is a decreasing function of the quality parameter $q$.

(b) When $p_{M} \geq 2((1-q) /(2-q))$, the demand $D_{M}\left(p_{M}\right)$ is independent of the market structure in the market for pirate copies, but when $p_{M}<2((1-q) /(2-q))$, $D_{M}\left(p_{M}\right)$ is a decreasing function of $k$.

(c) An increase in the fixed cost $F$ has a non-negative effect on $D_{M}\left(p_{M}\right)$. An increase in the advertising cost $b$ increases $D_{M}\left(p_{M}\right)$ if it does not affect the number of the bootleggers. If this is not the case, an increase in $b$ can also decrease $D_{M}\left(p_{M}\right)$.

According to part (c) of this proposition, an increase in the punishments for piracy can decrease the profits of the copyright owner also in the absence of network effects, which would make the market penetration of the product affect the value that it has for the consumers. This is because an increase in the "advertising cost" might increase the profits of the bootleggers and the number of the bootleggers who enter the market. I now turn to the optimization problem of the copyright owner, which is the problem of maximizing the revenue $R_{M}\left(p_{M}\right)=p_{M} D_{M}\left(p_{M}\right)$ where $D_{M}\left(p_{M}\right)$ is given by (33). It turns out that although the integral that occurs in (33) cannot be evaluated explicitly, the derivative of the revenue $R_{M}\left(p_{M}\right)$ has a surprisingly simple expression.

Proposition 4. The optimal price $p_{M}$ of legitimate copies is never such that some pirate copies would be so cheap that there would be no consumers who prefer buying 
a legitimate copy to buying one of them. If $p_{M}$ is such that this is not the case, and if there are pirate copies on the market,

$$
\frac{d R_{M}\left(p_{M}\right)}{d p_{M}}=1-\frac{2 p_{M}}{1-q}+\frac{2 p_{\min }}{1-q} .
$$

This proposition implies that for each fixed value of $k$ the derivative $d R_{M}\left(p_{M}\right) / d p_{M}$ has the value zero when

$$
p_{M}=p_{\min , k}+\frac{1-q}{2}
$$

where $p_{\min , k}$ denotes the minimum price of pirate copies for the given $p_{M}$ and $k$.

Further, together with the fact that $\partial p_{\min , k} / \partial p_{M}<0$ (see Proposition 2(a) above), this implies that for each $k$ there can be at most one value of $p_{M}$ for which (35) is valid.

However, the actual number of the pirates $k\left(p_{M}\right)$ is determined by $p_{M}$ in accordance with (3), and it is a non-decreasing function of $p_{M}$. According to Proposition 2(b), $p_{\min , k}$ is a decreasing function of $k$, and hence, the equilibrium value of $p_{M}$ determined by (35) is a decreasing function of $k$. These observations yield the following characterization of the equilibrium price $p_{M}$ of legitimate copies.

COROLlary 2. (a) Assume that there are $K=k$ potential bootleggers and that they do not have fixed costs. If there are pirate copies on the market in equilibrium, the equilibrium value of $p_{M}$ is determined by the condition (35).

(b) More generally, when there are $K$ potential bootleggers with fixed costs $F \geq 0$, there can be at most one value of $p_{M}$ for which (35) is valid with $k=k\left(p_{M}\right)$. The 
optimal choice of $p_{M}$ is either this value (if it exists) or the value that maximizes $R_{M}\left(p_{M}\right)$ in $\left\{\bar{p}_{M}(k) \mid k=0,1, \ldots, K-1\right\}$, where $\bar{p}_{M, k}$ denotes the largest price for which the number of the active bootleggers stays below $k$ :

$$
\bar{p}_{M, k}=\max \left\{p_{M} \mid P_{i}\left(p_{M} ; k\right) \leq F\right\} .
$$

Figure 2 illustrates the first part of this result. It shows the revenue curve $R_{M}\left(p_{M}\right)$ of the copyright owner when the number $k$ of the bootleggers is 0,1 , and 2 , and the limit of $R_{M}\left(p_{M}\right)$ when $k \rightarrow \infty$. In the situation of the figure the copyright owner would have to lower $p_{M}$ to the value $p_{M}^{\prime}$ in order to prevent the emergence of a market for pirate copies, and in equilibrium she will let all potential bootleggers enter. In the limit in which the number of the active bootleggers approaches infinity the optimal price $p_{M}$ of legitimate copies approaches the value $p_{M, \text { opt }}$ shown in Figure 2. [Place Figure 2 approximately here]

Figure 3 represents a situation in which the potential bootleggers have fixed costs, but that is similar in other respects. The dotted lines show the revenue of the copyright owner in the presence of 0,1 , and 2 bootleggers. The revenue curve of the copyright owner (which is shown as a solid line) has a discontinuity at the points $\bar{p}_{M, 1}$ and $\bar{p}_{M, 2}$ at which the number of the bootleggers changes. According to the latter part of the above corollary, the equilibrium value of $p_{M}$ is either one of the points of discontinuity or the maximum of the curve that corresponds to one of the values $k=0, k=1, \ldots$. Figure 3 illustrates the former possibility since in it the optimal price 
$p_{M}$ is the largest price that suffices to block the entry of the second bootlegger (i.e. $\left.\bar{p}_{M, 2}\right)$

[Place Figure 3 approximately here]

When the number of the bootleggers $k$ is fixed, according to Proposition 3(c) an increase of $b$ shifts the revenue curve $R_{M}\left(p_{M}\right)$ upwards, and hence, it must correspond to an increase of the revenue of the copyright owner. However, if $b$ is sufficiently small and $k \geq 2$, an increase of $b$ will increase the profits of the bootleggers. This decreases the $p_{M}$ values $\bar{p}_{M, 2}, \bar{p}_{M, 3}, \ldots$ at which the bootleggers enter, and if one of these values is the equilibrium value of $p_{M}$, this decreases of the revenue of the copyright owner in equilibrium.

The following corollary follows immediately from these observations and Proposition 3.

COROLlaRY 3. Suppose that the strategies of the copyright owner and the bootleggers form a Nash equilibrium of the game 1) - 4).

a) The revenue of the copyright owner is a non-decreasing function of the fixed cost $F$ and a decreasing function of $q$.

b) The revenue of the copyright owner is sometimes increased and sometimes decreased by an increase in the advertising cost $b$.

Hence, our earlier conclusion that an increase in the punishments for piracy might decrease the revenue of the copyright owner generalizes to the equilibriums of the 
model as a whole. I shall conclude this section by presenting some other comparative static results that are concerned with these equilibriums. Clearly, the comparative static properties of the model will be different in the equilibriums in which $p_{M}$ is optimal relative to some fixed number of bootleggers, and the "corner solutions" in which $p_{M}$ has the largest value sufficient to block the entry of one more bootlegger. In the following proposition, attention has been restricted to the equilibriums of the former kind. These equilibriums are the ones in which the revenue of the copyright owner is maximal also when the number of the active bootleggers is exogenously given, which corresponds to setting $F=0$.

PROPOSITION 5. Suppose that the strategies of the copyright owner and the bootleggers form a Nash equilibrium of a game of the form 1) - 4) in which $F=0$. Suppose further that there are $K=k$ active bootleggers who send advertisements.

(a) The price $p_{M}$ of legitimate copies and the minimum and maximum prices of pirate copies, $p_{\min }$ and $p_{\max }$, are decreased by an increase in $k$.

(b) When $k=1$, the prices $p_{M}$ and $p_{\max }$ are independent of $b$. When $k \geq 2$, the prices $p_{M}, p_{\max }$, and $p_{\min }$ are increasing functions of the advertising cost $b$, and

$$
\frac{d p_{M}}{d b}=\frac{d p_{\min }}{d b}
$$

(c) A raise in the quality parameter $q$ shifts $p_{M}$ downwards, but the derivatives $d p_{\max } / d q$ and $d p_{\min } / d q$ can be either positive or negative.

\section{Concluding Remarks}


The role of government policy and DRM systems in preventing commercial piracy was analyzed in a setting in which the profitability of piracy was restricted not just by these factors and the competition with the copyright owner, but also by the competition between the commercial pirates. The apparently puzzling fact that the prices of pirate copies do not always sink to zero via Bertrand competition between the pirates was explained by drawing a distinction between the different effects that government monitoring and DRM systems have on the illegal business model of the commercial pirate. The costs of breaking DRM systems and the expected costs of a punishment were viewed as consisting of a fixed cost of production and an "advertising cost". The "advertising cost" depends on the number of the consumers to whom a bootlegger (i.e., a commercial pirate) offers her products and it keeps the prices of pirate copies above their production costs.

The markets for legitimate and illegitimate copies of information goods were studied both when the copyright owner chooses the price of legitimate copies optimally and when this is not the case, for example, because of lack of information concerning the pirate copy market. The comparative statics of these markets was studied with respect to the quality of the pirate copies and the policy variables, which were the fixed and the variable costs of the bootleggers. Some of the results of this analysis were to be expected, but others were more surprising.

For example, it turned out that the revenue of the copyright owner is decreased by an increase in the quality of pirate copies both when the price of legitimate copies is optimal and when it is exogenously given, and that, as long as this does not affect the number of the bootleggers on the market, an increase in their "advertising costs" increases the revenue of the copyright owner and the prices of pirate copies. More 
interestingly, it also turned out that when there are several bootleggers on the market, an increase in the price of legitimate copies increases price dispersion in the market for pirate copies and decreases their minimum price. Since the pirate copies that have a very low price might be viewed as the counterpart of non-commercial forms of piracy in the current model, this result can be taken to mean that if the copyright owner chooses a sufficiently high price for an information good, it will simultaneously be subject to both commercial and non-commercial forms of piracy. Our analysis also revealed that the effects of the two policy variables on the revenue of the copyright owner were different: whereas it was always in the interest of the copyright owner that the fixed costs of the bootleggers were increased, this was not true of the "advertising costs" because an increase in the "advertising costs" might increase the profitability of commercial piracy and the incentive to enter the market for pirate copies. As the current model contains just a single information good without any network effects, this result is distinct from the familiar results that the producer of an information good might profit from piracy if this makes it easier to sell complementary goods or services to consumers ${ }^{20}$ or leads network effects that increase the popularity of the product. ${ }^{21}$

${ }^{20}$ For example, the demand for concerts by an artist might be increased by the pirate copies of her recordings (Gayer and Shy 2006). Somewhat less obviously, when the consumers do not know in advance which information products they prefer (e.g. to which musical recordings they would enjoy listening), the possibility to sample pirate copies might make them willing to pay more for their preferred product. See Peitz and Waelbroeck (2006b).

21 See Conner and Rumelt (1991, Proposition 4 on p. 133). 
Since the fixed costs of the bootleggers can be caused by technical protection devices whereas, at least in the case of commercial piracy on the Internet, the "advertising costs" result almost completely from the increased risk of a punishment, this result can be interpreted to mean that an improvement in the DRM systems that make an information good technically difficult to copy is always in the interest of the copyright owner, but this is not necessarily true of an increase in the legal protection of information goods.

I have not presented a detailed welfare analysis from which one could have deduced the optimal values of the policy variables of the model. Such an analysis is made problematic by the fact that it is not clear whether a social planner should aim at maximizing welfare that is obtained by illegal means, as through commercial piracy. I also have not analyzed the effects of piracy on the market penetration of the product, which would be quite essential if one wanted to include network effects in the current model. Inclusion of network effects would lead to several interesting questions that we have not considered. For example, above it was seen that an improvement in the quality of pirate copies tends to lower the revenue of the copyright owner, and it would be interesting to find out whether this effect could, in the presence of network effects, be balanced by the positive effects of the increase in market penetration that a quality improvement would cause. 


\section{APPENDIX. PROOFS OF PROPOSITIONS.}

Proof of Proposition 1. When one puts

$$
f\left(A_{i}, a_{i}, p\right)=p x(p) \exp \left(-\sum_{j \neq i} A_{j}(p)\right) e^{-A_{i}} a_{i}(p)
$$

the Euler equation, which must be valid in the interval $\left(p_{\min }, p_{\max }\right)$ for a function

$A_{i}(p)$ for which the function $R_{i}$ given by (12) obtains its maximum value, turns out to be

(A1) $\frac{\partial f}{\partial A_{i}}-\frac{d}{d p} \frac{\partial f}{\partial a_{i}}=0$.

This Euler equation is equivalent to

$$
-p x(p) \exp \left(-\sum_{j \neq i} A_{j}(p)\right) e^{-A_{i}} a_{i}(p)-\frac{d}{d p}\left[p x(p) \exp \left(-\sum_{j \neq i} A_{j}(p)\right) e^{-A_{i}}\right]=0
$$

and further to

$$
x(p)+p x^{\prime}(p)=p x(p) \sum_{j \neq i} a_{j}(p) .
$$

Since we are considering a symmetric equilibrium, it can be concluded that

$$
a_{i}(p)=\frac{1}{k-1}\left(\frac{1}{p}+\frac{x^{\prime}(p)}{x(p)}\right)
$$

and further that

$$
A_{i}(p)=\frac{1}{k-1} \int_{p_{\min }}^{p}\left(\frac{1}{u}+\frac{x^{\prime}(u)}{x(u)}\right) d u=\frac{1}{k-1} \ln \frac{p x(p)}{p_{\min } x\left(p_{\min }\right)}
$$

This proves the validity of (14).

The result (13) can be deduced from (14) by observing that (14) and (12) imply that 
(A4)

$$
\begin{aligned}
R_{i} & =\int_{p_{\min }}^{p_{\max }} p x(p)\left(\frac{p_{\text {min }} x\left(p_{\text {min }}\right)}{p x(p)}\right) e^{-A_{i}(p)} a_{i}(p) d p \\
& =p_{\text {min }} x\left(p_{\text {min }}\right)\left(1-e^{-A_{i}}\right)
\end{aligned}
$$

and that the profit of each bootlegger is given by

$$
P_{i}=R_{i}-b A_{i}=p_{\min } x\left(p_{\min }\right)\left(1-e^{-A_{i}}\right)-b A_{i}
$$

Since each bootlegger could choose to send arbitrarily many advertisements with the price $p_{\min }$ without having to compete with the other bootleggers, $A_{i}$ must have the value that maximizes profits for the given value of $p_{\min }$. In other words, in equilibrium it must be the case that

$$
\frac{\partial P_{i}}{\partial A_{i}}=p_{\min } x\left(p_{\min }\right) e^{-A_{i}}-b=0,
$$

so that

$$
A_{i}=\ln \frac{p_{\min } x\left(p_{\min }\right)}{b}=\ln \frac{r_{\min }}{b}
$$

On the other hand, the values of $A_{i}$ and $p_{\min }$ are connected also by the fact that the total number of the advertisements that the advertiser $i$ sends is $A_{i}\left(p_{\max }\right)$. The result (14) implies that

$$
A_{i}=A_{i}\left(p_{\max }\right)=\frac{1}{k-1} \ln \frac{p_{\max } x\left(p_{\max }\right)}{p_{\min } x\left(p_{\min }\right)}=\frac{1}{k-1} \ln \frac{r_{\text {max }}}{r_{\text {min }}} .
$$

Together the results (A6) and (A7) imply (13).

ProOf OF PROPOSITION 2. First it is observed that since by assumption $p_{\max } \geq p_{\min }>p_{M}+q-1,(19)$ implies that $p_{M}<2((1-q) /(2-q))$. Keeping this in mind, it is observed that part (a) of this proposition follows trivially from (13), (16), (19), (20), and (21), except for the statement that $\partial p_{\min } / \partial p_{M}<0$. It can be proved by 
observing that the when $k \geq 2$ and $p_{\min }>q+p_{M}-1$, the condition (13) (i.e. $\left.r_{\min }=b^{1-1 / k} r_{\max }^{1 / k}\right)$ can be expressed in the form

$$
\frac{\left(q p_{M}-p_{\min }\right) p_{\min }}{q(1-q)}=b^{1-1 / k}\left(\frac{q p_{M}^{2}}{4(1-q)}\right)^{1 / k}
$$

Hence,

$$
\frac{\left(q p_{M}-2 p_{\min }\right)}{q(1-q)} \frac{\partial p_{\min }}{\partial p_{M}}+\frac{p_{\min }}{1-q}=\frac{2}{k p_{M}} r_{\text {min }}
$$

and

$$
\begin{aligned}
& \frac{\left(q p_{M}-2 p_{\min }\right)}{q(1-q)} \frac{\partial p_{\min }}{\partial p_{M}}=p_{\min }\left(\frac{2 x\left(p_{\min }\right)}{k p_{M}}-\frac{1}{1-q}\right) \\
& =\frac{p_{\min }}{1-q}\left(\frac{2\left(q p_{M}-p_{\min }\right)}{q k p_{M}}-1\right)<0 .
\end{aligned}
$$

Since $q p_{M}-2 p_{\min }>q p_{M}-2 p_{\max }=0$, it now follows that $\partial p_{\min } / \partial p_{M}<0$.

The parts (b) and (c) of this proposition follows trivially from (13), (15), (16), (19), and (21), except for the claim concerning the profit $P_{i}$ of the bootleggers. In order to demonstrate it, we assume that $k \geq 2$ and observe that (18) and (13) imply that

(A8) $\frac{\partial P_{i}}{\partial b}=(1-1 / k) \frac{r_{\max }^{1 / k}}{b^{1 / k}}-1-\frac{1}{k} \ln \frac{r_{\max }}{b}+\frac{1}{k}$

and that

(A9) $\frac{\partial^{2} P_{i}}{\partial b^{2}}=-\frac{k-1}{k^{2}} \frac{r_{\max }^{1 / k}}{b^{1+1 / k}}+\frac{1}{k b}$.

This immediately implies that there is precisely one value of $b \in\left(0, r_{\max }\right]$ for which $\partial^{2} P_{i} / \partial b^{2}=0$, and this further implies that there are at most two values of $b \in\left(0, r_{\text {max }}\right]$ for which $\partial P_{i} / \partial b=0$. It is now observed that

(A10) $\left[\frac{d P_{i}}{d b}\right]_{b=r_{\max }}=(1-1 / k)-1+\frac{1}{k}=0$ 
so that within the interval $\left(0, r_{\max }\right)$, there can be at most one value of $b$ for which $\partial P_{i} / \partial b=0$. On the other hand, since the function $P_{i}$ is by construction positive in the interval $\left(0, r_{\max }\right)$, and since it has the limit 0 when $b \rightarrow 0$ and when $b \rightarrow r_{\max }$, it must be the case that $\partial P_{i} / \partial b=0$ for at least one value $b_{E} \in\left(0, r_{\max }\right)$. Hence, $P_{i}$ is an increasing function of $b$ when $b<b_{E}$ and that $P_{i}$ is a decreasing function of $b$ when $b>b_{E}$

Finally, turning to the part (d) of this proposition, all the statements in it also follow trivially from (13), (18), (19), (20) and (21), except for the statement concerning $\partial p_{\min } / \partial q$. It can be demonstrated by using (8) for expressing (13) in the form

$$
\frac{q p_{M}-p_{\min }}{q^{1+1 / k}(1-q)^{1-1 / k}} p_{\min }=\frac{b^{1-1 / k} p_{M}^{2 / k}}{4^{1 / k}}
$$

Since the right-hand side of this equation is constant for each constant value of $q$, it must be the case that (A11) $\left(\frac{q p_{M}-2 p_{\min }}{\left(q p_{M}-p_{\min }\right) p_{\min }}\right) \frac{\partial p_{\min }}{\partial q}=-\left(\frac{p_{M}}{q p_{M}-p_{\min }}-\frac{1+1 / k}{q}+\frac{1-1 / k}{1-q}\right)$.

Clearly, the multiplier of $\partial p_{\min } / \partial q$ in (A11) is always positive, but the term on the right-hand side is sometimes positive and sometimes negative: the right-hand side is negative, for example, when $k=2$ and $q>3 / 4$, but it has a positive value when $q \approx 0$ and $p_{\min } /\left(q p_{M}\right)$ is very small, since in this case

$$
-\left(\frac{p_{M}}{q p_{M}-p_{\min }}-\frac{1+1 / k}{q}+\frac{1-1 / k}{1-q}\right) \approx-\frac{1}{q}+\frac{1+1 / k}{q}=\frac{1}{k q} .
$$

This proves the statement that $\partial p_{\min } / \partial q$ is sometimes positive and sometimes negative. In order to prove the claim concerning its upper limit, we now introduce the 
notation $\gamma=p_{\min } /\left(q p_{M}\right)$ and observe that the right-hand side of (A11) can be positive only if

$$
\frac{1}{q(1-\gamma)}-\frac{1+1 / k}{q}+\frac{1-1 / k}{1-q}<0
$$

This is equivalent to

(A12) $\gamma<\frac{1 / k-q}{1-2 q+1 / k}$

The partial derivative $\partial p_{\min } / \partial p_{M}$ can be positive only when this condition is valid, and if this is the case,

$$
\frac{q p_{M}-2 p_{\min }}{q p_{M}-p_{\min }}=\frac{1-2 \gamma}{1-\gamma}>\frac{(1-2 q+1 / k)-2(1 / k-q)}{(1-2 q+1 / k)-(1 / k-q)}=\frac{1-1 / k}{1-q}>1-1 / k \geq \frac{1}{2}
$$

Hence, now one can conclude from (A11) that if $\partial p_{\min } / \partial p_{M}$ is positive,

$$
\frac{\partial p_{\min }}{\partial p_{M}}<2 p_{\min }\left(\frac{1+1 / k}{q}-\frac{p_{M}}{q p_{M}-p_{\min }}\right)<\frac{2 p_{\min }}{k q}
$$

Given that $p_{\min }<p_{\max }=q p_{M} / 2$ and that $k \geq 2$, it now follows that

$$
\frac{\partial p_{\min }}{\partial p_{M}}<\frac{p_{M}}{k}<\frac{1}{2}
$$

Proof OF Proposition 3. When $p_{M} \geq 2((1-q) /(2-q))$ the statements of this proposition follow trivially from (23) and the continuity of $D_{M}\left(p_{M}\right)$. Suppose then that $p_{M}<2((1-q) /(2-q))$. According to (33) in this case

(A14) $D_{M}\left(p_{M}\right)=1-\frac{p_{M}-p_{\min }^{\prime}}{1-q}+\frac{1}{p_{M}} \int_{p_{\min }^{\prime} / q p_{M}}^{1 / 2} f(z) d z+\frac{2 b}{p_{M}}$ where $f(z)=b /\left(4^{1 /(k-1)}(z(1-z))^{k /(k-1)}\right)$. Below $f(z)$ will be viewed as given by this formula for arbitrary real values of $k$ although, of course, (A14) has a meaningful 
economic interpretation only when $k$ is an integer. Clearly, (A14) is formally valid also when $k=1$, since in this case $p_{\min }^{\prime} /\left(q p_{M}\right)=p_{\max } /\left(q p_{M}\right)=1 / 2$, so that the integral on the right-hand side of (A14) vanishes.

When $p_{\min }^{\prime}=p_{M}+q-1,(\mathrm{~A} 14)$ implies that

$$
D_{M}\left(p_{M}\right)=\frac{1}{p_{M}} \int_{1 / p_{M}-\left(1-p_{M}\right) /\left(q p_{M}\right)}^{1 / 2} f(z) d z+\frac{2 b}{p_{M}}
$$

and it immediately follows that $\partial D_{M}\left(p_{M}\right) / \partial b>0$ and $\partial D_{M}\left(p_{M}\right) / \partial q<0$. When it is observed that $4 z(1-z)<1$ when $z<1 / 2$, it follows that

$$
\frac{\partial f(z)}{\partial k}=\frac{1}{z(1-z)} \frac{\partial}{\partial k}\left(\frac{1}{4 z(1-z)}\right)^{1 /(k-1)}<0,
$$

so also $\partial D_{M}\left(p_{M}\right) / \partial k<0$. This proves (a) and (b) when $p_{\min }^{\prime}=p_{M}+q-1$.

When $p_{\min }^{\prime}=p_{\min }$, the analysis of the considered partial derivatives is made more complicated by the implicit dependence of $p_{\min }$ on $b, q$, and $k$. However, (31) implies that

$$
f\left(\frac{p_{\min }}{q p_{M}}\right)=\frac{q p_{M}^{2}}{1-q}
$$

so one can conclude from (A14) that

$$
\frac{\partial D_{M}\left(p_{M}\right)}{\partial p_{\min }^{\prime}}=\frac{1}{1-q}+\frac{-1}{p_{M}\left(q p_{M}\right)} f\left(\frac{p_{\min }}{q p_{M}}\right)=0 ;
$$

this makes it legitimate to leave this dependence out of consideration below.

Now it follows that when $p_{\min }^{\prime}=p_{\min }$,

(A16) $\frac{\partial D_{M}\left(p_{M}\right)}{\partial b}=\frac{1}{p_{M}} \int_{p_{\min }^{\prime} / q p_{M}}^{1 / 2} \frac{\partial f(z)}{\partial b} d z+\frac{2}{p_{M}}>0$ 
so that the demand of the copyright owner is an increasing function of $b$. Further, since $\partial f(z) / \partial k<0$, it must be the case that

(A17) $\frac{\partial D_{M}\left(p_{M}\right)}{\partial k}=\frac{1}{p_{M}} \int_{p_{\min }^{\prime} / q p_{M}}^{1 / 2} \frac{\partial f(z)}{\partial k} d z<0$.

Finally, (A14) and (A15) together imply that

$$
\begin{aligned}
& \frac{\partial D_{M}\left(p_{M}\right)}{\partial q}=-\frac{p_{M}-p_{\min }}{(1-q)^{2}}-\frac{1}{p_{M}}\left(\frac{\partial}{\partial q}\left(\frac{p_{\min }}{q p_{M}}\right)\right) f\left(\frac{p_{\min }}{q p_{M}}\right) \\
& =-\frac{p_{M}-p_{\min }}{(1-q)^{2}}+\frac{1}{p_{M}} \frac{p_{\min }}{q^{2} p_{M}}\left(\frac{q p_{M}^{2}}{1-q}\right)=-\frac{p_{M}}{(1-q)^{2}}+\frac{1}{q(1-q)^{2}} p_{\min }<0 .
\end{aligned}
$$

This completes the proof of the parts (a) and (b) of the proposition. Turning to part (c), it is first observed that an increase in $F$ can affect the demand of the copyright owner only by decreasing $k$, and as it just has been proved, a decrease of $k$ has a nonnegative effect on $D_{M}\left(p_{M}\right)$. Finally, above it was seen that $\partial D_{M}\left(p_{M}\right) / \partial b>0$, so an increase in $b$ increases $D_{M}\left(p_{M}\right)$ if it does not affect the number of the active bootleggers. However, since according to Corollary 1(b) an increase in $b$ can increase $k$, and since an arbitrarily small change in $b$ can change $k$ by 1 , it must sometimes be the case that an increase in $b$ decreases $D_{M}\left(p_{M}\right)$.

Proof OF Proposition 4. First it is observed that if $p_{M}>2((1-q) /(2-q)),(23)$ immediately implies that $R_{M}\left(p_{M}\right)=p_{M} D_{M}\left(p_{M}\right)$ is a decreasing function of $p_{M}$ and that the copyright owner can increase her profits by lowering the price $p_{M}$. Suppose now that $p_{M} \leq 2((1-q) /(2-q))$. In this case (33) implies that

(A19) $R_{M}\left(p_{M}\right)=p_{M}\left(1-\frac{p_{M}-p_{\min }^{\prime}}{1-q}\right)+\int_{p_{\min }^{\prime} / q p_{M}}^{1 / 2} f(z) d z+2 b$ 
and the derivative of $R_{M}\left(p_{M}\right)$ is seen to be

(A20) $\frac{d R_{M}\left(p_{M}\right)}{d p_{M}}=\frac{d}{d p_{M}}\left[p_{M}\left(1-\frac{p_{M}-p_{\min }^{\prime}}{1-q}\right)\right]-\frac{d\left(p_{\min }^{\prime} / q p_{M}\right)}{d p_{M}} f\left(\frac{p_{\min }^{\prime}}{q p_{M}}\right)$.

If $p_{\min }^{\prime}=p_{M}+q-1$, this implies that

$$
\frac{d R_{M}\left(p_{M}\right)}{d p_{M}}=-\frac{d}{d p_{M}}\left(\frac{1-(1-q) / p_{M}}{q}\right) f\left(\frac{p_{\min }^{\prime}}{q p_{M}}\right)<0,
$$

and the copyright owner has an incentive to lower the price. Hence, in equilibrium $p_{\min }^{\prime}=p_{\min }>p_{M}+q-1$, and some consumers would buy a legitimate copy even if they could get a pirate copy for $p_{\min }$.

When $p_{\min }^{\prime}=p_{\min }$, the price $p_{\min }$ satisfies the condition (A15), and one can conclude from (A20) that

$$
\begin{aligned}
& \frac{d R_{M}\left(p_{M}\right)}{d p_{M}}=\left(1-\frac{2 p_{M}-p_{\min }}{1-q}\right)+\frac{p_{M}}{1-q} \frac{d p_{\min }}{d p_{M}}-\left[\frac{1}{q p_{M}} \frac{d p_{\min }}{d p_{M}}-\frac{p_{\min }}{q p_{M}^{2}}\right] \frac{q p_{M}^{2}}{1-q} \\
& =1-\frac{2 p_{M}-p_{\min }}{1-q}+\frac{p_{\min }}{1-q}=1+\frac{2 p_{\min }}{1-q}-\frac{2 p_{M}}{1-q} .
\end{aligned}
$$

This completes the proof. $\square$

Proof of Proposition 5. According to Proposition 2(b), for each value of $p_{M}$ the minimum price $p_{\min , k}$ is decreased by an increase in $k$. Hence, Proposition 4 implies that an increase in $k$ decreases the derivative $d R_{M}\left(p_{M}\right) / d p_{M}$ for each value of $p_{M}$, so the value of $p_{M}$ for which $d R_{M}\left(p_{M}\right) / d p_{M}=0$ grows smaller if $k$ increases. Now (19) and (35) imply that $p_{\max }$ and $p_{\min }$ will also decrease. This proves part (a) of the proposition.

Turning to part (b), (35) is written in the form 
(A21) $p_{M}(q, b, k)=p_{\min }\left(p_{M}, q, b, k\right)+\frac{1-q}{2}$.

When $k=1, p_{\min }=p_{\max }$ is for each fixed value of $p_{M}$ independent of $b$, so that the solution of this equation is also independent of $b$. Suppose then that $k \geq 2$.

Differentiating (A21) with respect to $b$ one gets

(A22) $\frac{d p_{M}}{d b}=\frac{\partial p_{\min }}{\partial b}+\frac{\partial p_{\min }}{\partial p_{M}} \frac{d p_{M}}{d b}$.

According to Proposition $2, \partial p_{\min } / \partial p_{M}<0$ and $\partial p_{\min } / \partial b>0$, and one can conclude from (A22) that

$$
\frac{d p_{\min }}{d b}=\frac{d p_{M}}{d b}=\frac{\partial p_{\min } / \partial b}{1-\partial p_{\min } / \partial p_{M}}>0 .
$$

Now (19) implies that also $d p_{\max } / d b>0$. Finally, (A21) also implies that

(A23) $\frac{d p_{M}}{d q}=\frac{\partial p_{\min }}{\partial q}+\frac{\partial p_{\min }}{\partial p_{M}} \frac{d p_{M}}{d q}-\frac{1}{2}$.

Since $\partial p_{\min } / \partial q<1 / 2$ according to Proposition 2(d), this implies that

$$
\frac{d p_{M}}{d q}=\frac{\partial p_{\min } / \partial q-1 / 2}{1-\partial p_{\min } / \partial p_{M}}<0
$$

It must still be demonstrated that no similar general results are valid for $d p_{\max } / d q$ and $d p_{\min } / d q$. In the case of $d p_{\max } / d q$, perhaps the easiest way to see this is to observe that (as one can demonstrate by elementary means) when $k=1, \quad p_{M}=(1-q) /(2-q)$ and $p_{\max }=q(1-q) /(2(2-q))$, and that the sign of $d p_{\max } / d q=(d / d q)[q(1-q) /(2(2-q))]$ depends on the value of $q$. Assume then that $k \geq 2$. Clearly, (A23) implies also that

(A24) $\frac{d p_{\min }}{d q}=\frac{d p_{M}}{d q}+\frac{1}{2}=\frac{\partial p_{\min } / \partial q-1 / 2}{1-\partial p_{\min } / \partial p_{M}}+\frac{1}{2}$, 
so since $1-\partial p_{\min } / \partial p_{M}>1, d p_{\min } / d q$ must be positive whenever $\partial p_{\min } / \partial q$ is positive.

Perhaps the easiest way to see that $d p_{\min } / d q$ can be negative is to assume that $k$ is very large and to write the condition (A21) in the form

(A25) $\frac{q p_{M}-p_{\min }}{(1-q) q}=\frac{1}{2}-\frac{p_{\min }}{q}$.

Clearly, the left-hand side of this equation equals $x\left(p_{\min }\right)$, and in the limit in which $k \rightarrow \infty$ it will be the case that $x\left(p_{\min }\right) p_{\min }=b$. Hence, in the limit in which $k \rightarrow \infty$,

$$
\left(\frac{1}{2}-\frac{p_{\min }}{q}\right) p_{\text {min }}=p_{\text {min }} x\left(p_{\min }\right)=b .
$$

Clearly, the left-hand side of this equation is an increasing function of both $q$ and $p_{\min }$, but the right-hand side is a constant, immediately implying that when $k$ is sufficiently large, $d p_{\min } / d q$ must be negative. 


\section{REFERENCES}

Andrés, A. R., 2006. The relationship between copyright software protection and piracy: Evidence from Europe. European Journal of Law and Economics 21, 2951.

Banerjee, D. S., 2003. Software piracy: A strategic analysis and policy instruments. International Journal of Industrial Organization 21, 97-127.

Banerjee, D. S., 2006a. Lobbying and commercial software piracy. European Journal of Political Economy 22, 139-155.

Banerjee, D. S., 2006b. Enforcement sharing and commercial piracy. Review of Economic Research on Copyright Issues 3, 83-97.

Butters, G. R., 1977. Equilibrium distributions of sales and advertising prices. The Review of Economic Studies 44, 465-491.

Chen, Y., I. Png, I., 2003. Information goods pricing and copyright enforcement: Welfare analysis. Information Systems Research, 14, 107-123.

Conner, K. R., Rumelt, R. P., 1991. Software piracy: An analysis of protection strategies. Management Science 37, 125-139.

Eskicioglu, A. M., Delp, J. E., 2001. An overview of multimedia content protection in consumer electronics devices. Signal Processing: Image Communication 16, 681699.

Gayer, A., Shy, O., 2006. Publishers, artists and copyright infringement. Information Economics and Policy 18, 374-384.

Park, Y., Scotchmer, S., 2005. Digital rights management and pricing of digital products. NBER Working Paper Series 11532. 
Peitz M, Waelbroeck, P., 2006a. Piracy of digital products: A critical review of the theoretical literature. Information Economics and Policy 18, 449-476.

Peitz, M, Waelbroeck, P., 2006b. Why the music industry may gain from free downloading - the role of sampling. International Journal of Industrial Organization, 24, 907-913.

Tirole, J. 1989. The Theory of Industrial Organization. Third Printing. Cambridge, MA: The MIT Press.

Varian, H. R., 1980. A model of sales. The American Economic Review 70, 651-659.

Varian, H. R., 2000. Buying, sharing, and renting information goods. The Journal of Industrial Economics 48, 473-488.

Yao, J.-T., 2005. Counterfeiting and an optimal monitoring policy. European Journal of Law and Economics 19, 95-114. 


\section{FIGURES}

This paper contains three figures which are reproduced on the three pages that follow, and which have the following captions:

Figure 1. The profit $P_{i}$ of each bootlegger as a function of the "advertising cost" $b$ for some values of $k$ when $p_{M}=1 / 3$ and $q=2 / 3$.

Figure 2. The revenue curve of the copyright owner for some values of $k$ when $b=0.002, q=0.5$, and $F=0$.

Figure 3. The revenue curve of the copyright owner when $b=0.002, q=0.5$, and $F=0.001$. 


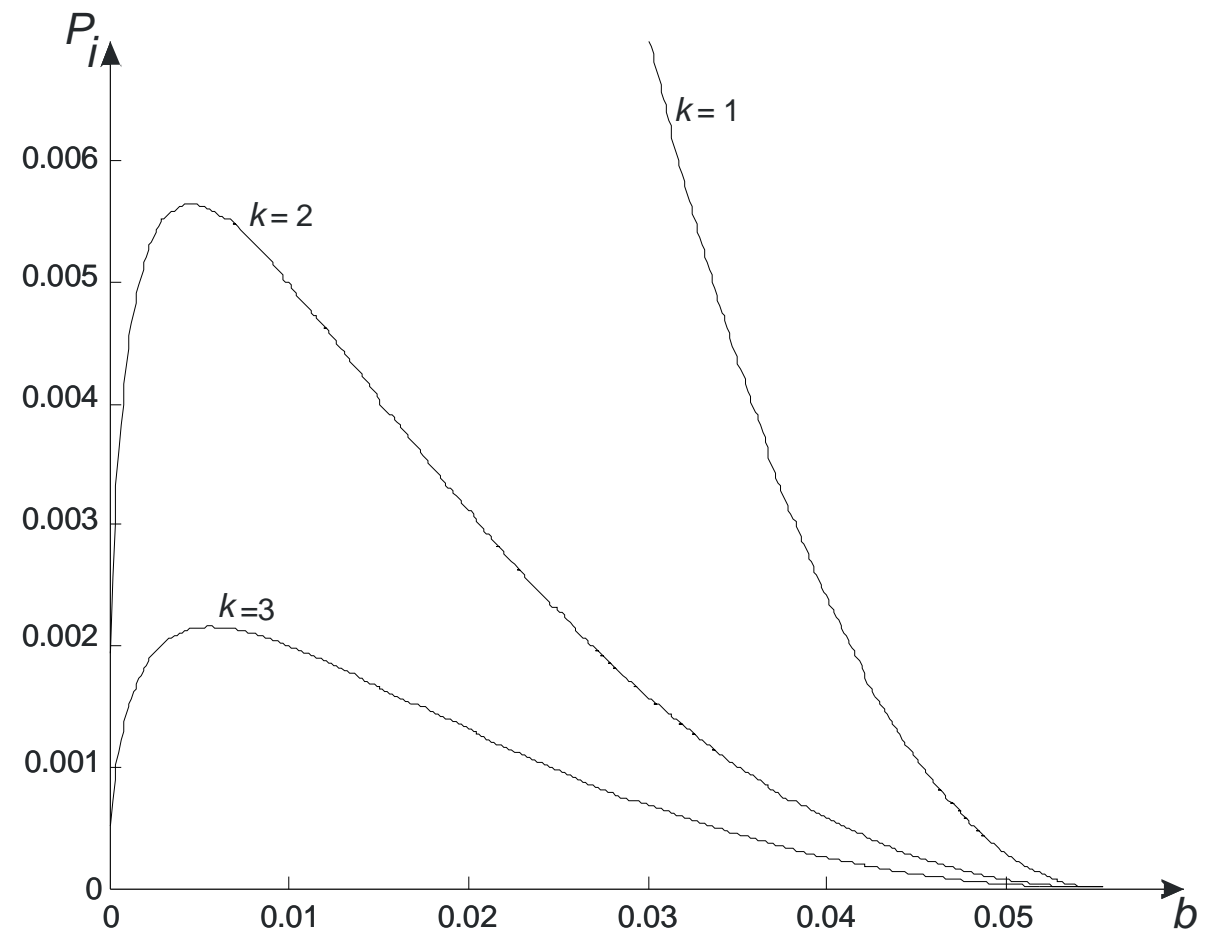

FIGURE 1. 


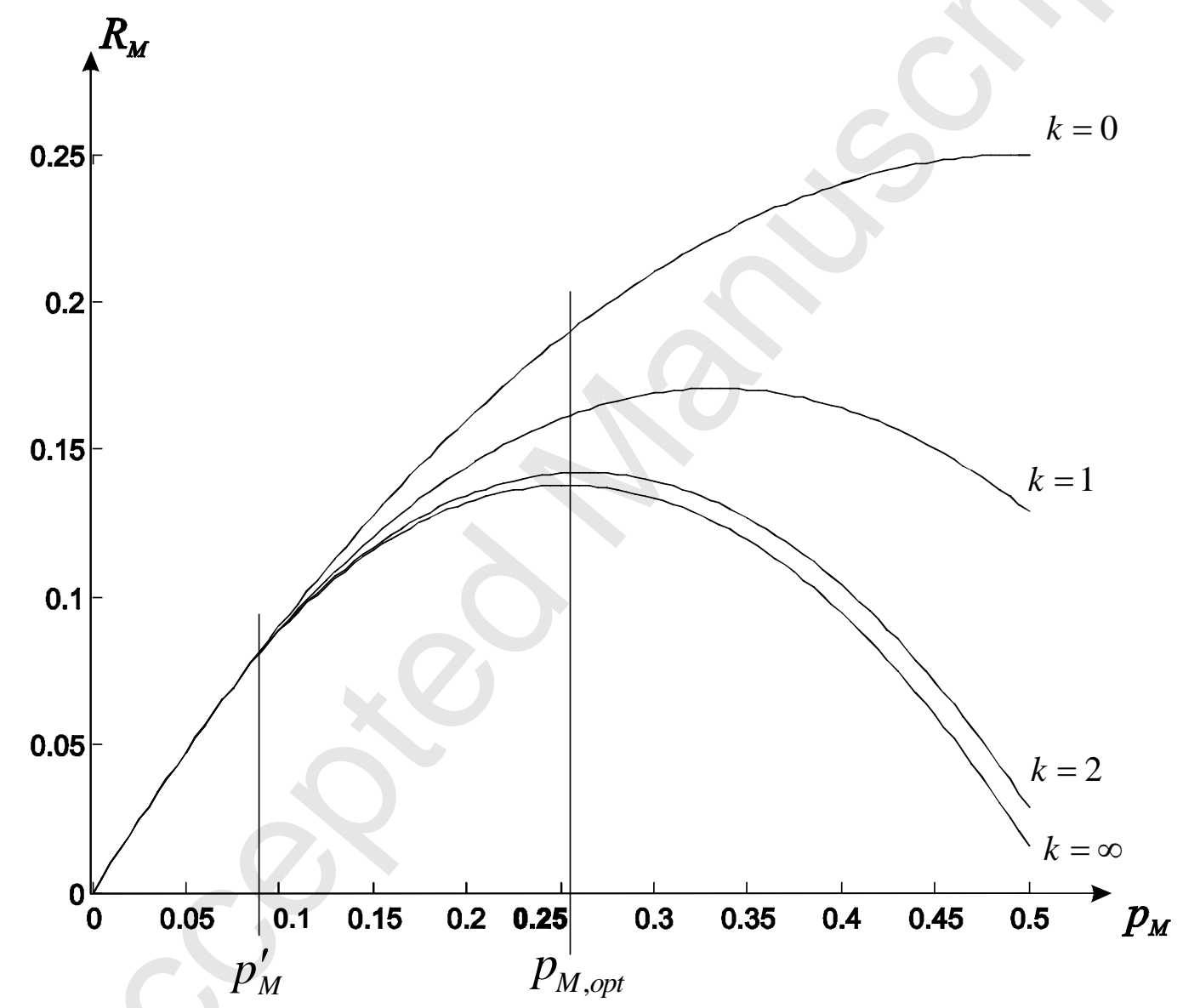

FIGURE 2 


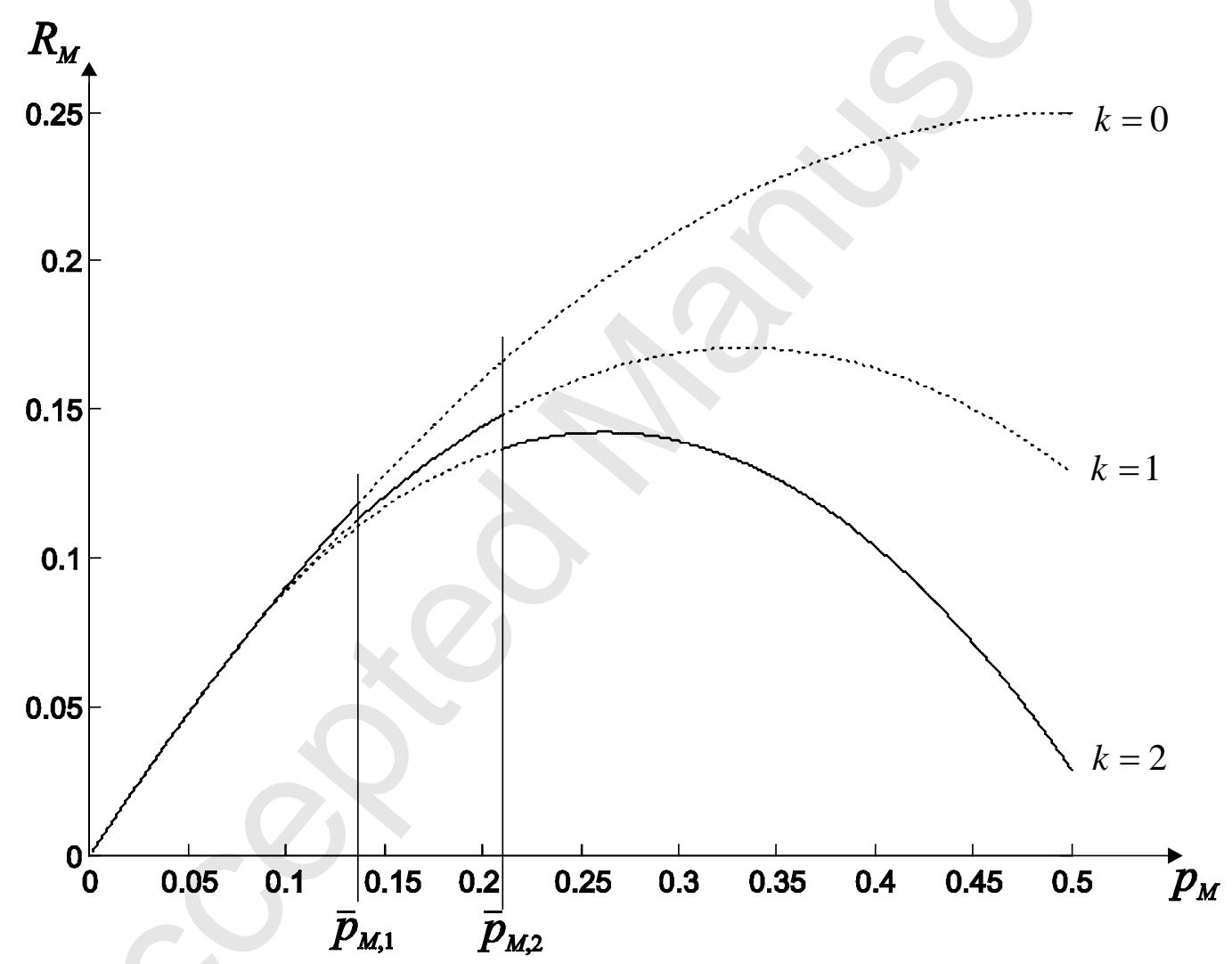

FIGURE 3. 